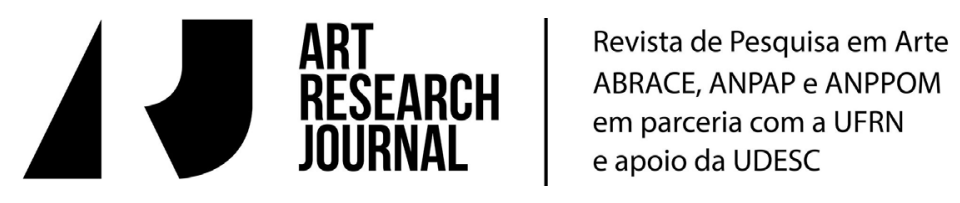

\title{
A metáfora acontece na imaginação do espectador - sobre "Aesthetics of Absence - texts on theatre" de Heiner Goebbels
}

Stephan Baumgartel

Universidade Estadual de Santa Catarina - UDESC

GOEBBELS, Heiner. Aesthetics of Absence. Original alemão: Ästhetik der Abwesenheit por Theater de Zeist, 2012. Seleção e edição de Jane Collins, Tradução para o inglês de David Roesner e Christina M. Lagao. London \& New York: Routledge, 2015. 111p. ISBN: 978-1-415-83104-8

Talvez desde o início do século XX, mas certamente desde os anos 1960, as diferentes linguagens artísticas (cênicas, visuais, musicais) sofrem uma espécie de diluição de suas fronteiras. Na esteira deste processo, não somente o status do objeto artístico, seus alcances e seus modos de confecção sofreram grandes alterações, mas também (e inevitavelmente) as concepções daquilo que costumamos chamar de experiência estética. Se para alguns a arte deve aproximar-se da vida e até fundir-se com ela, para outros a criação de novas formas interativas de relacionar o fenômeno artístico e seus receptores deve basear-se na manutenção dessas fronteiras, mesmo que seja apenas para investigar seus contornos, sua validade e seus impactos. Ou seja, uma experiência estética é possível apenas quando a lacuna entre arte e vida é problematizada, mas de algum modo respeitada ${ }^{1}$. Pois a partir do momento em que a arte perca sua dimensão simbólica mediadora, ela também perde a capacidade de criar intervenções simbólicas e performativas críticas da vida e da consciência empíricas dos diversos participantes do evento artístico. Em última análise, a arte perde sua capacidade de oferecer a seus recipientes uma experiência reflexiva da coexistência entre liberdade e sociabilidade no ato criativo da recepção.

\footnotetext{
${ }^{1}$ Ver Rebentisch, 2012.
} 
Com seu livro Aesthetics of Absence, Heiner Goebbels se inscreve no grupo daqueles que insistem na produtividade constitutiva de uma relação de distância e proximidade diferenciadas entre arte e vida. Mas o faz não para encerrar o fazer artístico na famosa torre de marfim idealizada (que muitas vezes é apenas idílica e escapista), senão para liberar em obras artísticas concretas a possibilidade de impactos perturbadores e inovadores sobre nossas percepções estéticas tão frequentemente normatizadas por uma tradição não interrogada ou por instituições formativas que atendem a essa tradição.

Em vários momentos de seu livro, Goebbels discursa sobre a importância de sair das convenções formais não só do teatro moderno, mas também de um teatro performativo contemporâneo que se baseia na expressividade do corpo do ator e na intensidade de seus atos cênicos. Critica formas teatrais que buscam preencher o palco com suas verdades de tal maneira que o espectador não possa mais imaginar e descobrir nada. Por isso, ele fala da necessidade de construir lacunas desestabilizadoras entre materialidades e significados; de configurar distâncias entre objetos cênicos ou entre diversas linguagens cênicas que instigam a curiosidade investigativa dos espectadores. Além disso, Goebbels investe em compor vínculos estruturais entre esses elementos separados que evitem que um seja apenas a ilustração ou a concretização do significado do outro. É uma busca "pelo conteúdo das formas. Uma investigação sobre o que as formas fazem conosco. As formas com quais nos arranjamos e convivemos em toda parte; que não chegam a um nível de consciência e por isso possuem tanto poder sobre nossa percepção" ( $p$. xxiv). A obra de Goebbels surge nessa coletânea como uma constante busca por novas formas cênicas que permitem experiências estéticas e perceptuais inusitadas por configurar, a partir de um determinado tema, relações cênicas inovadoras. ${ }^{2}$ O título de sua coletânea de textos sobre o teatro, Estética da Ausência (sem pronome!), recebe seu sentido concreto nessa perspectiva. Goebbels busca compor arranjos cênicos que minam os desejos do espectador de espelhar-se narcisisticamente nos acontecimentos do palco (p.32), seja por meio de uma relação simbólico-hermenêutica ou imaginária-sensorial. Para tal, é fundamental a ausência de um centro semântico estável que confira certeza aos significados cênicos ou aos processos de recepção. Sempre há algum aspecto particular em cena que dificil-

\footnotetext{
${ }^{2}$ Para informar-se melhor sobre a concretude cênica da obra de Goebbels, sugiro acessar o material disponível no site https://vimeo.com/search?q=heiner+goebbels (acesso em 5 de janeiro de 2016)
} 
mente pode (e nem deve) ser integrado no todo da experiência estética e que faz parte dela enquanto elemento potencialmente inassimilável e contraditório, fonte tanto de uma sensação de perturbação quanto de liberdade. Não é de se surpreender que as relações cênicas sejam pensadas por Goebbels ao longo do livro como sendo simultaneamente poéticas e sociais (sobretudo em suas reflexões sobre o compositor Hans Eisler e o conjunto musical Ensemble Modern).

O livro apresenta três grandes blocos temáticos. O primeiro reúne palestras e ensaios de Goebbels sobre algumas de suas próprias encenações ao longo dos últimos vinte anos. Neles, o autor explica seus processos de criação e, sobretudo, a visão artística subjacente a sua poética cênica. Na segunda parte, o livro apresenta alguns textos sobre artistas com quais Goebbels sente uma espécie de afinidade artística eletiva: o cineasta Jean-Luc Godard, o coletivo teatral Rimini Protokoll, os diretores e cenógrafos Robert Wilson e Erich Wonder, e o Ensemble Modern, uma cooperativa autogerida de músicos eruditos. Por fim, há um bloco com ensaios nos quais Goebbels reflete sobre as dificuldades e os desafios que um projeto formativo artístico precisa enfrentar nos cursos técnicos e universitários, a fim de inculcar nos estudantes uma curiosidade estruturada e hábil que permite seu engajamento em investigações laboratoriais cênicas que possam levar à criação de um teatro enfaticamente contemporâneo (e assim construir a prática cênica do futuro). Nessa terceira parte entram reflexões inspiradas pela experiência de sua docência permanente no Instituto para Ciências Teatrais Aplicadas da Universidade Gießen, fundado em 1982 pelo pesquisador polonês Andrzej Wirth com a ajuda de Hans-Thies Lehmann. O Instituto se destaca no cenário universitário alemão pela combinação única entre prática artística e reflexão teórica.

Alguns eixos temáticos atravessam todos os três segmentos do livro, o que permite deduzir que são temas e concepções estruturantes para a visão e a criação artísticas de Goebbels. São esses, sobretudo, a concepção do encenador não como um artista que monta uma concretização interpretativa de um material textual ou cria uma organicidade para as materialidades da cena. Antes, ele é um artista que sabe organizar uma conversa entre as diferentes linguagens cênicas cuja estruturação provoca e interpela a percepção e a atividade interpretativa do espectador. Como o título já indica, Goebbels reiteradamente concebe o palco como um espaço sem centro e sem hierárquica, marcada por lacunas e tensões e por procedimentos que deslocam e até dispersam a atenção do espectador perante um espaço 
cênico que distribui e divide o que costumamos chamar de presença teatral entre todas as linguagens cênicas. Nesse sentido, os textos de Goebbels mostram um desinteresse na concepção moderna de presença como efeito baseado na energia expressiva do corpo físico do ator; como um modo enfático do ator de estar-emcena, supostamente autêntico enquanto artista e verdadeiro enquanto personagem. De fato, o que lhe interessa é menos "a presença" expressiva de uma figura ou de uma linguagem (e com a qual o público poderia se identificar), senão "o presente" enquanto fluxo em constante mutação, composto do surgir e do esvanecer de elementos de igual importância que captam a atenção do espectador e que o interpelam ou provocam de maneiras diversas e possivelmente contraditórias. ${ }^{3}$

Esse deslocamento fica perceptível na ênfase que ele coloca na dimensão acústica do evento cênico. Na introdução, Goebbels afirma que "talvez não seja a 'ausência' que se tornou a dimensão cênica primordial para mim, senão o deslocamento da presença do campo visual para o campo acústico. Pois no palco acústico (tanto das obras do teatro musical quanto das composições musicais ou das peças radiofónicas) pode haver interrupções, contrapontos e lacunas, mas nada é realmente 'ausente'" (p. xxiv). Mas nada, tampouco, contribui para que se apresente em cena uma obra orgânica capaz de evocar uma sensação de experiência aurática. Goebbels se interessa pela colaboração das diferentes linguagens como linguagens separadas ou em assincronia. ${ }^{4}$

De fato, o livro não oferece uma "estética da ausência". Não explica possíveis fundamentos epistemológicos para essa estética, nem define sua possível estrutura sistemática. Mas esclarece o interesse de Goebbels no parâmetro da ausência e explica como trabalha com ele em suas diversas composições cênicas. Entre esses procedimentos, Goebbels cita numa lista mais associativa do que sistemática, en-

\footnotetext{
${ }^{3}$ Há um ponto de contato interessante com o pensamento de Lehmann acerca da performatividade no teatro pós-dramático. Lehmann propõe formular a presença "como presente do teatro, [...] como processo, como verbo. Ela não pode ser objeto nem substância. [...]. Contentamo-nos com a compreensão desse presente como algo que acontece. [...]. Esse presente não é um ponto do agora coisificado numa linha do tempo; ele ultrapassa esse ponto num incessante desvanecer e, ao mesmo tempo, é cesura entre o passado e o porvir. O presente é, necessariamente, erosão e escapada da presença. Ele designa um acontecimento que esvazia o agora e, nesse mesmo vazio, faz brilhar a recordação e a antecipação (Lehmann, 2007, p. 239, tradução adaptada após comparação com o texto alemão). Goebbels obviamente não fala no "brilho" da recordação e da antecipação, mas também enfoca o vazio no presente no qual os elementos anteriores e posteriores continuam a reverberar ("nada é realmente ausente"). Além disso, a recepção afetiva e interpretativa de qualquer obra cênica, feita ao vivo em tempo real, trabalha necessariamente com procedimentos de recordação e antecipação.

${ }^{4}$ De certa maneira, podemos ler o livro como um desdobramento e um a radicalização do pensamento estrutural de Bernard Dort em "A representação emancipada" (2013).
} 
tre outros, (1) a divisão da atenção entre diversos focos simultâneos; (2) modos de fazer os performers oscilarem entre individualização e desindividualização; (3) processos de separação e de dessincronização entre as diferentes linguagens cênicas (vozes de seus corpos e a lógica visual da lógica acústica da cena); (4) a criação de lacunas, ou pausas, tanto sensoriais quanto semânticas, nas quais a imaginação e a reflexão podem se apoiar; (5) a criação de uma ausência enfática concreta de um elemento cênico tradicional (de atores/performers em cena, de uma história ou de qualquer expressividade cênica) e (6) o ato de evitar elementos formais conhecidos.

A ausência, nesse sentido, surge nas reflexões de Goebbels como procedimento para garantir que o evento cênico possa desenvolver todo seu potencial de acontecimento, a fim de criar um impacto desestabilizador que instala a possibilidade de uma experiência nova.

O que motiva o autor a propagar a criação de uma poética da ausência ou de uma poética no qual o centro permanece vazio é, em última análise, uma aposta no teatro como um lugar social em que se organiza o encontro com uma alteridade, ou seja, com algo desconhecido. Seu teatro busca assumir esse lugar da alteridade: "Teatro como 'a coisa em si', não como representação ou como meio para criar enunciados sobre a realidade, isso é exatamente o que tento oferecer" (p. 2, tradução minha) ${ }^{5}$. Para que essa oferta possa ser bem recebida, Goebbels pressupõe e busca um espectador curioso, aberto e imaginariamente ativo que descobre outras realidades poéticas (e sociais) possíveis ao exercer essas habilidades em diálogo com uma apresentação semanticamente aberta, mas não arbitrária. A ideia de ausência corresponde à falta de um enquadramento semântico e poético estabelecido. Um projeto poético que busca impossibilitar uma relação narcisista com as imagens da cena. Se não há centro semântico em cena, tampouco se pode projetar uma única recepção como "central".

Portanto, nas modalidades formais desse encontro se revela também uma sociabilidade dos espectadores e uma ética inscrita tanto na poética cênica quanto no processo de recepção. A ausência de um centro semântico, portanto de uma

\footnotetext{
${ }^{5}$ Todas as traduções são feitas a partir de uma leitura comparativa das edições alemãs e inglesas. A numeração de páginas se refere sempre à edição inglesa.
} 
interpretação totalizante da cena, provoca os espectadores a usufruir da atividade receptiva como um exercício da própria liberdade por meio da imaginação, da investigação, da atenção flutuante e da interpretação heurística que não pode encontrar uma âncora em perspectivas pré-existentes e em interesses narcisistas. Para Goebbels, experiência artística é concebível apenas nestas modalidades de uma curiosidade investigativa e de um encontro aberto com o surpreendente, o desconhecido, o (ainda) incompreensível. Não há liberdade no construção e recepção do evento cênico sem a coexistência dessa dimensão desestabilizadora. Apenas nessas modalidades, o teatro pode oferecer a si mesmo como a experiência de um possível encontro com o outro.

A partir de sua instalação cênica Stifters Dinge, Goebbels reflete sobre a relação entre presença e ausência na configuração do encontro cênico:

\begin{abstract}
Ao invés de oferecer ao performer e ao espectador a possibilidade de uma autoafirmação, o "teatro da ausência" abre uma experiência artística que não consiste no encontro direto (com o ator), mas na experiência que passa pela alteridade. Alteridade aqui deve ser compreendida não como uma conexão direta com algo, mas antes como uma relação triangular indireta, na qual se substitui a identificação teatral por uma confrontação precária com um terceiro elemento mediador; algo que podemos chamar de "outro". Ausência como presença do outro; como encontro com uma imagem não vista ou uma palavra ou som inauditos; como encontro com forças que o ser humano não pode controlar e que se encontram fora de nosso alcance instrumental (p. 6).
\end{abstract}

Nesse último aspecto reside também o núcleo (proto-)político da experiência artística, na medida em que sua abertura e inconclusividade, dada pela ausência de um centro semântico organizador das diferentes linguagens cênicas, a estabelece como uma experiência subversiva em relação a qualquer contexto social normativo. Na medida em que a cena se apropria de elementos oriundos da vida social histórica para expor a ausência de uma relação óbvia entre eles e convidar o espectador a criar diversas relações entre esses elementos, ela se opõe á lógica da percepção imposta por contextos totalizantes.

Por outro lado, há certo perigo (ou talvez tentação) de ler esse encontro com as "forças fora de nosso alcance instrumental" erroneamente como apologia de uma poética pós-moderna de cunho irracional que naturaliza supostas impotências humanas perante um curso abstrato e mecânico da história; de ler esse fascínio como 
um impulso escapista dentro de uma visão de cultura intimista e contemplativa. Mas uma leitura atenta percebe que Goebbels desenvolve sua poética da ausência como uma espécie de antídoto contra os impactos de qualquer sistema fechado no qual a existência singular não importa nada perante as exigências do sistema como um todo. Por isso, esse pensamento (que encontramos, sobretudo, nas referências a Gertrude Stein e Elias Canetti e cujos textos Goebbels usa como material verbal e aural em dois trabalhos dele) se dirige tanto contra a lógica opressiva e totalizante da sociedade do espetáculo capitalista quanto à das sociedades fascistas ou das burocracias de cunho stalinista.

Mais ainda, surge do conjunto das reflexões de Goebbels uma proposta de buscar em cada formação social aqueles elementos particulares que apresentam um funcionamento disfuncional, para trabalhar com essa particularidade disfuncional em cena. Dificilmente a poética da não-presença (ou da presença constantemente dividida e deslocada) de Goebbels se oferece a um projeto poético cujo foco dominante é o reencantamento da experiência artística ou - menos ainda - do mundo empírico. Antes, trata-se de uma poética cênica que reivindica e garante um respeito para com as coisas minúsculas enquanto elementos disfuncionais dentro dos sistemas fechados. Dessa maneira, usando as palavras de Elias Canetti citadas por Goebbels, o diretor alemão propõe uma espécie de "atenção utópica, [...] que percebe todo elemento em pé de igualdade, até o que aparenta ser o mais marginal. Trata-se de nada menos que a utopia de um equilíbrio. [...] Canetti consegue criar um estado de atenção que é simultaneamente profundamente político e pessoal" (p. 21).

De fato, a poética da ausência oferece à nossa percepção continuamente elementos desconhecidos e configura uma composição cênica cuja totalidade sempre nos escapa no fluxo de seus elementos singulares. Portanto, seu funcionamento serve como metáfora que nos coloca perante a questão de como viver juntos sem um fundamento claro e sem chão comum predefinido, mas também sem hierarquias claramente estabelecidas. Ou seja, como viver juntos num mundo feito por uma teia de relações preponderantemente imanentes. Pois o funcionamento dessa poética - enquanto combinação de diferentes elementos particulares que expõe as fissuras e incongruências entre eles e entre as linguagens às quais pertencem - nos apresenta essa problemática num contexto imanente. Nas composições cênicas de Goebbels não há mais um princípio compositivo fora do arranjo cênico que possa 
oferecer um enquadramento estético a priori e ordenar os signos e objetos cênicos em uma composição hierárquica. A afirmação iterada de Goebbels de que ele não costuma trabalhar a partir de uma ideia artística preconcebida, mas a partir e com as condições de trabalho e de materialidades encontradas revela que há uma profunda identidade entre visão poética e modos de produção em sua obra. Em ambos os contextos, as estruturas são pouco hierárquicas e seguem uma relação interna quase dialética, no sentido de que há uma troca reflexiva constante entre as concepções poéticas e as condições concretas da construção do espetáculo, entre a busca formal mais genérica e as particularidades concretas do momento de criação específico.

A partir da relação imanente das linguagens cênicas, os espectadores não mais assistem - na concepção de Goebbels - a um drama ficcional controlado formalmente por um olhar externo de um diretor onipoderoso. Eles tampouco assistem a um evento performativo espetacular cuja forma é controlada pelo artista em ação ou dominado por uma única linguagem cênica. Antes, a partir da interação dos diferentes elementos presentes em cena, os espectadores produzem sua própria versão desse evento performativo. Junto com essa "edição" surge a consciência do próprio trabalho perceptual. Pois, ao tentar lidar com o surgimento dos elementos desconhecidos e com a alteridade que eles configuram, os espectadores se encontram com suas próprias modalidades de percepção, sentem-se confrontados com o drama da própria percepção. Numa guinada autorreferencial típica para as práticas artísticas contemporâneas, Goebbels destaca esse efeito crítico do teatral da ausência: "Em tal teatro, o espectador é antes parte do drama de sua própria experiência do que observador de uma ação dramática, na qual figuras representam no palco situações psicologicamente motivadas" (p. 2).

Um enfoque autorreferencial também influencia os cinco ensaios sobre a formação, ou melhor, sobre a educação de futuros artistas. Eles giram em torno da convicção de que é primordial envolver o estudante enquanto ser humano criativo no drama da construção de uma "inteligência artística própria" (p. 78), o que Goebbels vê como fundamental para que os jovens artistas possam ser de fato cúmplices de um processo de criação coletiva, e não apenas executores (por mais bem treinados que sejam) que seguem instruções. Enquanto artistas com responsabilidade própria que aprenderam a refletir sobre o papel cambiante de sua arte nos diferentes 
contextos históricos e artísticos, eles também sabem organizar um processo de investigação artística que usa os diferentes métodos, técnicas e procedimentos de uma maneira inovadora e exploradora, para além dos limites formais e das normas poéticas das instituições estabelecidas (p. 80). Limites que são determinados, segundo Goebbels, com demasiada frequência por parâmetros de uma atuação dramática e de uma experiência teatral calcada num encontro presencial com uma situação orgânica e um corpo (ficcional) de expressividade intensa (p. 85).

Essa terceira parte permite tecer algumas reflexões acerca das semelhanças e diferenças entre as situações alemãs e brasileiras que determinam até certo ponto a possibilidade ou necessidade de uma criação de poéticas da ausência. Em diversos momentos do livro de Goebbels, fica claro que ele desenvolve sua busca por uma estética da ausência não apenas a partir de um espírito vanguardista como fim em si mesmo. Antes, há um diálogo crítico e inclusive subversivo com um contexto estético contemporâneo marcado, por um lado, por um impacto residual das instituições burguesas com suas poéticas modernas e, por outro lado, por um impacto dominante dos aparelhos midiáticos da sociedade do espetáculo. Aesthetics of Absence é um livro dirigido contra ambas as influências, em busca de uma poética contemporânea emergente que possa solapar a validade das estruturas de sentimento e dos modos de percepção (para aplicar uma diferenciação de Raymond Williams) associados a eles. É um livro que afirma implicitamente a inutilidade de uma poética moderna (dramática e épica!) para superar a estética do espetáculo social do capitalismo atual. De fato, pressupostos e ideias como "intensidade cênica" ou "presença" fomentam também a estrutura das imagens e do sentimento da sociedade do espetáculo. A estética da ausência busca elaborar estruturas cênicas que provoquem uma recepção estética e social que não cabe mais nos contextos dessa sociedade do espetáculo. As esparsas referências a Brecht e suas reflexões sobre as relações entre os modos de produção e o entrelaçamento não-orgânico das linguagens encontram aqui sua função. Uma frase de Georges Didi-Huberman, citada por Goebbels (p.42), me parece resumir o projeto crítico, tanto artístico quanto pedagógico, do artista alemão, sobretudo se pensamos que o sujeito de que se fala na citação é esse sujeito burguês sob influência do encantamento espetacular. Diz Didi-Hubermann em O que vemos, o que nos olha: "Dar a ver é sempre inquietar o ver, em seu ato, em seu sujeito" (p. 77).

O problema no contexto brasileiro me parece ser o de como criar essa inquietação 
de modo concreto e não abstrato. Como confrontar essas poéticas da ausência e suas linguagens cênicas autonomas, criadas a partir das possibilidades técnicas mais recentes, com a realidade social brasileira e com a das práticas cênicas brasileiras? Como enriquecer esses processos com conteúdos tanto poéticos quanto sociais e com procedimentos cênicos que, querendo ou não, remetem mais a uma poética da miséria e da bricolagem artesanal do que a uma poética de tecnologias avançadas em espaços cênicos hipermodernos e formalmente limpos? Como incluir dados precisos da realidade brasileira no fluxo do presente dessa ausência sem centro?

Seria necessário que se identifique as diferenças e semelhanças entre as estruturas de sentimento hegemônicas no Brasil e na Alemanha (ou talvez da Europa Central o que inclui a Suiça, os países francófonos e nórdicos, mas não os países latinos) atuais, em relação às maneiras como cada sociedade se insere na formação capitalista contemporânea, para poder responder a tarefa não só de como apropriar-se de modo responsável das ideias de Goebbels, mas também de como dialogar criticamente com o conteúdo social dessa forma cênica.

No contexto alemão, esse conteúdo social aponta para um contexto cultural marcado por uma forte presença não só das vanguardas modernas, mas também da cultura moderna burguesa de caráter racionalista e centralizante, bem como um contexto social e político marcado por uma política de instituições fortes comprometidas com um projeto de bem-estar social. Enquanto vertente de uma vanguarda contemporânea europeia, a Estética da Ausência se dirige criticamente contra essa tradição cultural moderna. Para isso, lança mão dos meios técnicos e dos suportes reflexivos disponibilizados pela própria cultura moderna que está sendo questionada. Na medida em que as formas cênicas brasileiras são inseridas em um contexto socioeconômico marcado por desigualdades sociais, por relações de poder em boa parte ainda pré-modernas, tradições de reflexão menos solidificadas e pouco difundidas na população, e custos tecnológicos elevados e muitas vezes não financiáveis no nível europeu, um projeto cênico brasileiro que procura levar a sério a ideia de que cada forma cênica apresenta um conteúdo social vai permitir que seja marcado por essa realidade, configurando assim expressões dessa poética da bricolagem e da miséria ${ }^{6}$.

\footnotetext{
${ }^{6}$ Não se trata de uma qualificação de características de excelência artística. Mas seria um esforço vão e pouco orgânico, pois condenado a criar um abismo claro entre o fazer cênico e seu contexto
} 
Além dessas considerações sociais e macroeconômicas, fica claro que o contexto artístico e institucional teatral no Brasil se configura de maneira diferente. Se a prática do teatro de grupo e dos processos colaborativos que reivindicam a necessidade de processos laboratoriais quase configura o processo cênico dominante no Brasil - e não a exceção, como constata Goebbels em relação ao contexto alemão -, tal prática é marcada aqui no Brasil por uma extrema vulnerabilidade financeira. Portanto, é importante perceber que a radicalidade da proposta de Goebbels está no conceito poético que precisa ser usado dentro de um contexto financeiro diferente.

Quando a exigência de pesquisa está sendo atendida parcialmente pelos editais das instituições de fomento, isso ainda não garante a esse teatro uma abrangência para além da própria classe - algo que Goebbels toma como um impacto dado, pois o teatro faz parte da chamada esfera pública na Alemanha desde o século XVIII. A falta de impacto no Brasil não se dá por causa de uma falta de qualidade artística, mas, sobretudo, pelo fato de que o campo teatral não possui uma relevância simbólica dentro da vida social brasileira que é influenciada muito mais pelos produtos da chamada indústria cultural (da qual o teatro em sua grande maioria não faz parte já que é produzido e financiado de maneira artesanal). Nessas condições, entretanto, não podia se criar uma forte tradição de um teatro moderno contra o qual um teatro contemporâneo desenvolve sua investigação subversiva, como aconteceu na Europa. Além disso, se no contexto alemão e europeu central, a tradição teatral estabelecida exige certo rigor e estrutura na prática laboratorial, essa exigência não marca com o mesmo peso o contexto teatral brasileiro, dada a fragilidade tanto da tradição do drama burguês quanto de uma recepção sistemática dela e de outras linguagens artísticas contemporâneas, para não falar do caráter bastante recente de qualquer pesquisa cênica institucional no Brasil. Isso pode instaurar um caráter excessivamente eclético das práticas de investigação cênica e determinar ainda mais seu status ornamental na vida cultural brasileira. Qualquer recepção das ideias de Goebbels por um público brasileiro deve levar em conta essas diferenças contextuais culturais, para evitar que essas ideias sejam recebidas como ideias em sintonia com um propósito cultural burguês de encantamento do mundo e de edificação pessoal.

Por isso, me parece fundamental entender que Goebbels pressupõe como objetivo

sociocultural, se algum/a artista aspirasse apropriar-se das ideias de Goebbels com o mesmo aprimoramento técnico e a mesma perfeição no uso das novas mídias. 
de suas composições tensionar a percepção estabelecida por seu público alvo. A escolha do material e dos procedimentos cênicos não segue apenas uma pesquisa poética e cénica, mas uma finalidade de intervenção subversiva nos padrões perceptuais e simbólicos estabelecidos. A questão primordial a se fazer, então, me parece ser a de que tipo de ausência necessita(m) a(s) cena(s) teatral(ais) brasileira(s). Quais temas precisam ser escolhidos e que formato de ausência simbólica pode criar um impacto desestabilizador nesse contexto? Algo que não se pode responder concretamente sem avaliar a situação política e econômica do país, a estrutura socioeconômica e a subjetividade hegemônica que mantêm o país e seu sistema político em funcionamento. Pois é a subjetividade dominante - ou deveríamos dizer, a consciência que fundamenta o poder dominante - que uma poética da ausência, tal como concebida por Goebbels, procura solapar e privar de qualquer fundamentação.

\section{Referências}

DIDI-HUBERMAN, Georges. O que vemos, o que nos olha. Tradução de Paulo Neves. São Paulo: Editora 34, 1998.

DORT, Bernhard. A representação emancipada. Tradução de Rafaella Uhiara. Sala Preta. v. 13, n. 1, 2013, p. 47-55.

GOEBBELS, Heiner. Aesthetics of Absence. Trans. David Roesner e Christina M. Lagao. London\& New York: Routledge, 2015.

LEHMANN, Hans-Thies. Teatro Pós-dramático. Tradução de Pedro Süsskind. São Paulo: Cosac\& Naify, 2007.

REBENTISCH, Juliane. Aesthetics of Installation Art. Berlin: Sternberg Press, 2012. 